\title{
Effect of exposure time ratio on Intermittent Aerated Moving Bed Biofilm Reactor
}

\author{
He Wang and Hui-qiang $\mathrm{Li}^{*}$ \\ College of Architecture and Environment, Sichuan University, Chengdu 610065 Chengdu, China.
}

\begin{abstract}
This study combined the IA craft, and the goal is to achieve aerobic, anoxic and even anaerobic alternating cycles in the same reactor to enhance biological nitrogen and phosphorus removal. At present, there are many studies on the IA process, but less research on the IAMBBR craft. The IAMBBR craft combines intermittent aeration with a biofilm process, which can further improve the processing capacity of a continuous-flow biofilm reactor. Therefore, it is necessary to conduct a detailed study of the IAMBBR craft. In addition, the exposure time ratio is an important parameter for the operation of the IA craft. By adjusting the exposure time ratio, the DO concentration in the reactor can be controlled, which affects the operation effect of the reactor. Therefore, this chapter mainly explores the effect of exposure time ratio on the operating effect of IAMBBR. Six operating stages were connected: the ratio of CA and exposure time are $3 \mathrm{~h} / 3 \mathrm{~h}, 1 \mathrm{~h} / 1 \mathrm{~h}$, $30 \mathrm{~min} / 30 \mathrm{~min}, 15 \mathrm{~min} / 15 \mathrm{~min}$, and $5 \mathrm{~min} / 5 \mathrm{~min}$, respectively, to study the removal effect of pollutants.
\end{abstract}

\section{Introduction}

In recent years, with the increasingly strict discharge standards for municipal wastewater treatment plant, a large number of municipal wastewater treatment plants are in urgent need of upgrading $[1,2]$. In addition, most of the plants have problems of high energy consumption and high operating costs, and energy conservation. And consumption reduction of sewage treatment process is also imperative [3]. Therefore, how to improve nitrogen and phosphorus removal efficiency and reduce energy consumption in municipal wastewater treatment plants is a hot spot in wastewater treatment field. Moving bed biofilm reactor (MBBR) has the same structure as the activated sludge process, and it has the characteristics of lower cost, shorter time-consuming during the upgradation [4]. Moreover, MBBR process can improve the treatment load and effluent water quality after upgrading, and lower the operating cost [5]. Therefore, MBBR is one of the preferred processes for the upgrading of wastewater treatment plants. However, slow biofilm formation rate during startup stage is one of the stumbling blocks of MBBR, and there is space for improvement of nitrogen and phosphorus removal efficiency. The combination of MBBR technology and intermittent aeration (IA) technology can not only improve the nitrogen and phosphorus removal efficiency, but also promote the energy saving and consumption reduction of the sewage treatment plant. There have been a lot of researches on MBBR, but few research and application on IAMBBR or similar process. Singh et al. [6] used a biofilm / activated sludge mixing process to study the effect of exposure time ratio on pollutant removal under high aeration. The results show that IA craft has an important effect on the removal of nitrogen, and has a smaller effect on phosphorus and organic carbon. Luostarinen et al. [7] used an MBBR reactor to treat the mixture of anaerobic pre-treated dairy wastewater, kitchen wastewater and black water at low temperature. The effect of continuous flow and sequential batch on the sewage treatment effect under IA condition and CA condition were compared. The results showed that all the reactors could achieve complete nitrification, with the removal of TN and COD reaching 50\% 60\% and 40\% $\sim 70 \%$. The denitrification effect in IA was slightly higher than that in CA.

From the current research, IAMBBR and similar crafts can achieve high-efficiency denitrification in many cases. However, most of its current researches use sequential batch method (ie, IASBBR), and there is less research on IAMBBR treatment of domestic sewage. Therefore, it is necessary to carry out systematic research on the treatment of domestic sewage by IAMBBR to provide strong support for its engineering application.

\section{Material and methods}

The reactor is made of plexiglass with a size of $30 \times 10 \times 30$ $\mathrm{cm}$ and an effective volume of 8.20 L. Water inlets and outlets are provided at the lower left and upper right of the reactor, respectively. Simulated wastewater enters the reactor from the lower left, and overflows out of the reactor after the treatment. The filler chooses K1 type biological filler, its size is $\Phi 10 \times 10 \mathrm{~mm}$, density is $0.96 \sim 0.98 \mathrm{~g} / \mathrm{cm}^{3}$, and specific surface area is about $1200 \mathrm{~m}^{2} / \mathrm{m}^{3}$ with $30 \%$ biofiller fill rate. During the experiment, a thermostat was used to control the reactor temperature to $25 \pm 2{ }^{\circ} \mathrm{C}$, and a

\footnotetext{
* Corresponding author: lhq-scu@163.com
} 
time relay was used to control intermittent aeration at regular intervals. The aeration amount during the aeration period was $0.2 \mathrm{~m}^{3} / \mathrm{h}$. This experiment uses artificial simulated wastewater which contained glucose $(300 \mathrm{mg} / \mathrm{L})$, ammonium chloride (125 mg/L), sodium bicarbonate (100 $\mathrm{mg} / \mathrm{L})$, urea (40 mg/L), sodium dihydrogen phosphate (20 $\mathrm{mg} / \mathrm{L})$, potassium dihydrogen phosphate $(2 \mathrm{mg} / \mathrm{L})$ and trace elements $(1 \mathrm{ml} / \mathrm{L})$. To optimize the exposure time ratio, the optimal exposure time ratio group is selected and the optimization of the exposure time ratio is performed, based on the study of the startup process. HRT is $8 \mathrm{~h}$ at this stage. Study the differences in pollutant removal effect under different exposure time ratios: $3 \mathrm{~h} / 3 \mathrm{~h}, 1 \mathrm{~h} / \mathrm{h}$, $30 \mathrm{~min} / 30 \mathrm{~min}, 15 \mathrm{~min} / 15 \mathrm{~min}, 5 \mathrm{~min} / 5 \mathrm{~min}$, and CA stage.

\section{Results}

\subsection{Analysis of pollutant removal effect}

The COD, $\mathrm{NH}_{4}{ }^{+}-\mathrm{N}, \mathrm{TN}$ and $\mathrm{TP}$ concentrations of the influent in this study were $315 \pm 10 \mathrm{mg} / \mathrm{L}, 31 \pm 2 \mathrm{mg} / \mathrm{L}, 51$ $\pm 1 \mathrm{mg} / \mathrm{L}$, and $5.7 \pm 0.2 \mathrm{mg} / \mathrm{L}$, and the HRT was $8 \mathrm{~h}$, temperature is $25 \pm 2{ }^{\circ} \mathrm{C}$. It mainly examines the removal effect of pollutants under six stages, among which stage 1 is the exposure stopping time ratio $3 \mathrm{~h} / 3 \mathrm{~h}$, stage 2 is the exposure stopping time ratio $1 \mathrm{~h} / 1 \mathrm{~h}$, stage 3 is the exposure stopping time $30 \mathrm{~min} / 30 \mathrm{~min}$, stage 4 is the exposure time ratio $15 \mathrm{~min} / 15 \mathrm{~min}$, stage 5 is the exposure time ratio $5 \mathrm{~min} / 5 \mathrm{~min}$, and stage 6 is the CA stage.

\subsubsection{Analysis of DO concentration change trend}

The change in DO concentration has an important effect on the activity and metabolic pathways of microorganisms. Fig. 1 shows the change trend of DO concentration in the reactor under different exposure time ratios. It can be seen from the figure that with the change of the exposure time ratio, the DO concentration in the reactor has a large difference. In stage 1 , the DO concentration in the reactor varied between 0.1 and $3.5 \mathrm{mg} / \mathrm{L}$, where the $\mathrm{DO}$ concentration was greater than $2 \mathrm{mg} / \mathrm{L}$ for 180 minutes. In stage 2 , the DO concentration in the reactor varied between 0.1 and $3.7 \mathrm{mg} / \mathrm{L}$, where the DO concentration was greater than $2 \mathrm{mg} / \mathrm{L}$ and shortened to 75 minutes. In stage 3 , the DO concentration in the reactor varied between 0.1 to 3.2 $\mathrm{mg} / \mathrm{L}$, where the DO concentration was greater than 2 $\mathrm{mg} / \mathrm{L}$ and shortened to 28 minutes. In stage 4 , the DO concentration in the reactor varies between $0.1 \sim 3.2 \mathrm{mg} / \mathrm{L}$. In stage 5 , the DO concentration in the reactor varies between 1.4 and $2.5 \mathrm{mg} / \mathrm{L}$. In CA stage, the DO concentration of the reactor was maintained at about 4.8 $\mathrm{mg} / \mathrm{L}$.

\subsubsection{Effect of exposure time ratio on $C O D$ concentration in effluent}

Fig. 2 shows the effect of exposure time ratio on COD effluent concentration. As the exposure time ratio decreased from $3 \mathrm{~h} / 3 \mathrm{~h}$ to continuous aeration, the COD effluent concentration fluctuated between $20-40 \mathrm{mg} / \mathrm{L}$, and was always lower than $50 \mathrm{mg} / \mathrm{L}$. The COD concentration of the effluent in the aeration phase is similar to that in the cessation aeration phase, which indicates that the effect of the aeration time on the removal of organic matter is relatively slight. Previous studies have also shown that under low organic loads, intermittent aeration has less effect on the activity of heterotrophic microorganisms [8].

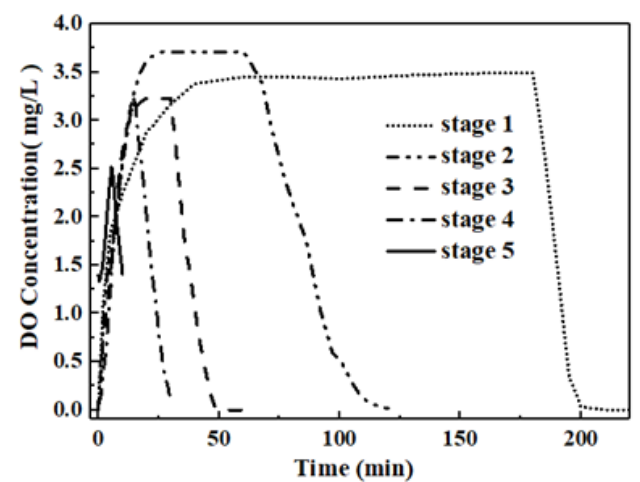

Fig. 1. Effect of oxic/anoxic on DO concentration

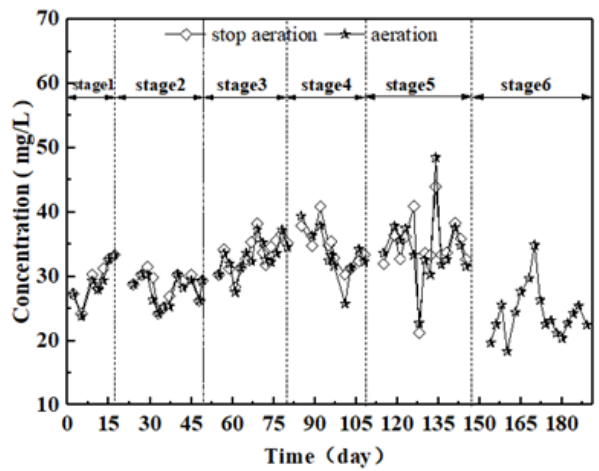

Fig. 2. Effect of oxic/anoxic on COD concentration in effluent

\subsubsection{Effect of exposure time ratio on conversion effect of nitrogenous pollutants}

Fig. 3 shows the changes of $\mathrm{NH}_{4}{ }^{+}-\mathrm{N}, \mathrm{NO}_{3}^{-}-\mathrm{N}, \mathrm{NO}_{2}^{-}-\mathrm{N}$ and TN concentrations over time at different exposure time ratios. The exposure time ratio has a greater effect on the $\mathrm{NH}_{4}^{+}-\mathrm{N}$ concentration in the effluent. With the shortening of the exposure time ratio, the $\mathrm{NH}_{4}{ }^{+}-\mathrm{N}$ concentration in the effluent increased first and then decreased. When the exposure time ratio was $15 \mathrm{~min} / 15 \mathrm{~min}$ (stage 4 ), the effluent concentration reached the highest, about $23 \mathrm{mg} / \mathrm{L}$ In continuous aeration conditions, the concentration of $\mathrm{NH}_{4}{ }^{+}-\mathrm{N}$ effluent is the lowest, about $10 \mathrm{mg} / \mathrm{L}$. The results show that the exposure time is greater than the removal impact of $\mathrm{NH}_{4}{ }^{+}-\mathrm{N}$. The removal effect of $\mathrm{NH}_{4}{ }^{+}-\mathrm{N}$ is poor under CA stage due to the fact that the concentration of TN and organic nitrogen in the water is higher, and the HRT is shorter. At $2.5 \mathrm{mg} / \mathrm{L}$, the $\mathrm{NH}_{4}{ }^{+}-\mathrm{N}$ concentration in the effluent is as high as $19.6 \mathrm{mg} / \mathrm{L}$. The removal of $\mathrm{NH}_{4}{ }^{+}-\mathrm{N}$ mainly depends on the nitrifying bacteria to oxidize $\mathrm{NH}_{4}{ }^{+}-$ $\mathrm{N}$ to $\mathrm{NO}_{3}^{-}-\mathrm{N}$ under aerobic conditions. The decrease in DO concentration during the aeration period has a greater impact on the nitrification ability, resulting in an increase in $\mathrm{NH}_{4}{ }^{+}-\mathrm{N}$ concentration in the effluent effluent. In addition, it can be clearly seen from Fig. 3 that when the 
exposure time is relatively long, such as stage 1 , the difference in $\mathrm{NO}_{3}{ }^{-}-\mathrm{N}$ concentration in the effluent during the aeration phase and the aeration phase was $6 \mathrm{mg} / \mathrm{L}$. Therefore, a relatively long exposure time can easily lead to unstable water quality.

With the shortening of the exposure time ratio, the concentration of effluent $\mathrm{NO}_{2}^{-}-\mathrm{N}$ showed a downward trend, from about $2 \mathrm{mg} / \mathrm{L}$ to about $0.2 \mathrm{mg} / \mathrm{L}$. $\mathrm{NO}_{2}^{-}-\mathrm{N}$ is mainly produced by ammonia oxidation and removed by nitrification and denitrification. Compared with NOB, $\mathrm{AOB}$ has a stronger affinity for oxygen, and AOB recovers relatively quickly at low DO concentrations. In addition, in the anoxic environment, the decay rate of AOB is also lower than that of NOB. Stopping the aeration stage can greatly reduce the system's oxidation ability to $\mathrm{NO}_{2}^{-}-\mathrm{N}$. Previous studies have also reported that intermittent aeration can effectively inhibit the activity of NOB, thereby achieving the accumulation of $\mathrm{NO}_{2}^{-}-\mathrm{N}$. In IA stage the accumulation of $\mathrm{NO}_{2}^{-}-\mathrm{N}$ is greater than that under the CA stage, and as the exposure time ratio is shortened, the $\mathrm{NO}_{2}^{-}-\mathrm{N}$ concentration in the effluent is decreasing.
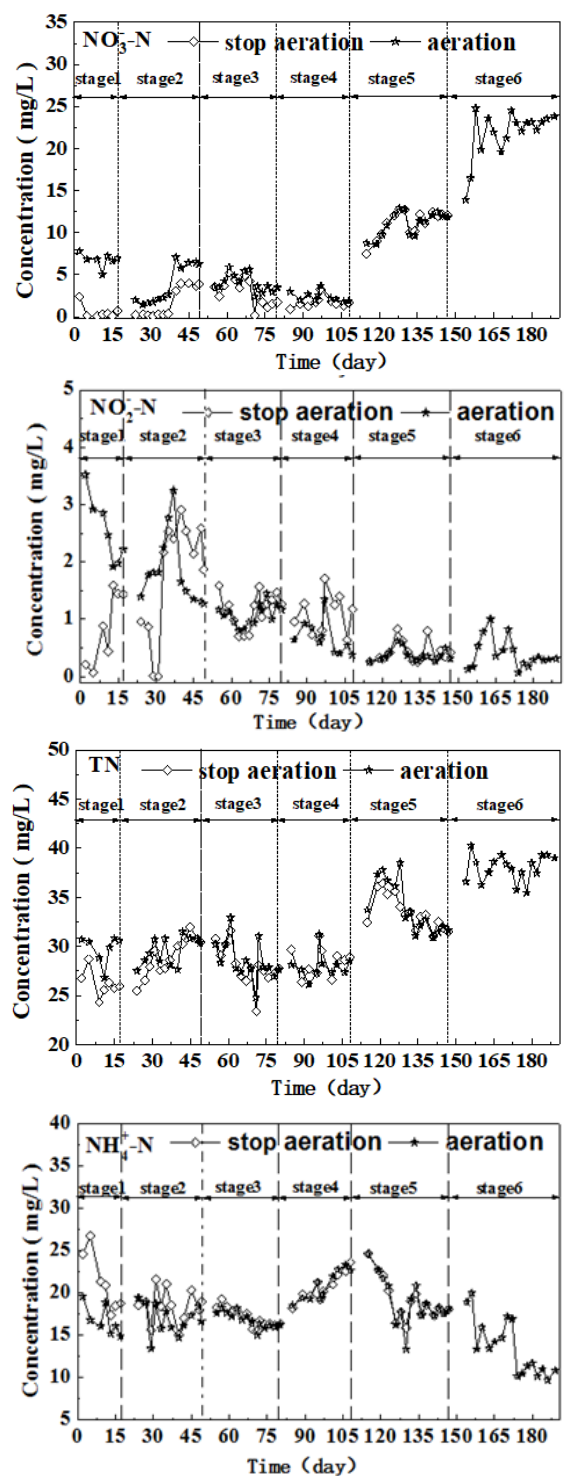

Fig. 3. Effect of oxic/anoxic onNH+4-N、NO- 3-N 、 NO- 2-N and $\mathrm{TN}$ concentration in effluent
The TN concentration of the effluent decreases first and then increases with the shortening of the exposure time ratio. Generally, In most sewage treatment systems, the removal of TN mainly depends on the denitrification of denitrifying bacteria. An alternating environment of aerobic and hypoxic conditions is formed in the IA stage. In the aerobic phase, it is beneficial to the nitrification process, and in the anoxic phase, it is beneficial to the denitrification process. In the exposure time ratios of $3 \mathrm{~h} / 3 \mathrm{~h}$ (stage 1) and $1 \mathrm{~h} / 1 \mathrm{~h}$ (stage 2 ), due to the relatively long exposure stop time, the effluent quality of the aeration phase and the aeration stop phase are unstable, and the TN concentration in the effluent is large different. With the reduction of the exposure time ratio, the actual hypoxic environment duration of the system is shortened, and denitrification is hindered, leading to a reduction in the denitrification effect. Therefore, at CA stage (stage 6), the $\mathrm{TN}$ concentration in the effluent rose to $39 \mathrm{mg} / \mathrm{L}$. When the exposure time ratio is $30 \mathrm{~min} / 30 \mathrm{~min}$ (stage 3 ), the TN effluent concentration reaches the lowest, about $27 \mathrm{mg} / \mathrm{L}$, and the removal rate is about $45 \%$, which is about $24 \%$ higher than the total nitrogen removal rate under CA stage. Previous studies on intermittent aeration have also shown that IA stage is more conducive to $\mathrm{TN}$ removal than $\mathrm{CA}$ stage which is attributed to that in the process of intermittent aeration, the system forms an aerobic and anoxic alternating cycle environment, which provides feasible conditions for simultaneous nitrification and denitrification.

\subsubsection{Effect of exposure time ratio on TP concentration in effluent}

Fig.4 shows the effect of the exposure time ratio on the TP concentration in the effluent. With the reduction of the exposure time ratio, the TP concentration in the effluent showed a clear upward trend, from $3.26 \mathrm{mg} / \mathrm{L}$ to $4.03 \mathrm{mg} / \mathrm{L}$. Biological phosphorus removal is usually enhanced by anaerobic and aerobic processes. Microorganisms decompose their own polyphosphates under anaerobic environment to produce ATP to maintain their own activities. At this stage, microorganisms release phosphorus into the solution. When this part of the microorganisms changes from anaerobic environment to aerobic environment, PAOs will absorb a large amount of phosphorus in solution and store it in the form of polyphosphate in the body, and the amount of phosphorus absorbed in this process is greater than the amount of phosphorus released in anaerobic environment Therefore, intermittent aeration is beneficial for phosphorus removal. It can also be seen from Fig.4 that the effluent phosphorus concentration in the IA stage is lower than that in the CA stage. In the exposure time ratio of $3 \mathrm{~h} / 3 \mathrm{~h}$ (stage 1 ), the results are similar to previous studies. 


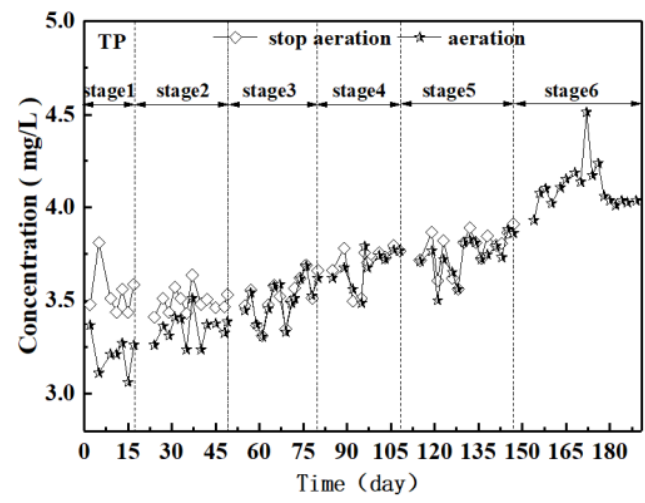

Fig. 4. Effect of oxic/anoxic on TP concentration in effluent

\section{Conclusions}

The effect of intermittent aeration on the removal of COD is slight, and the COD concentration in the effluent of the CA stage is slightly lower than that in the IA stage. The length of the aeration stop time ratio has an important effect on the stability of the effluent. When the aeration stop time ratio is less than $1 \mathrm{~h} / 1 \mathrm{~h}$, the difference between the effluent quality of the aeration phase and the aeration stop phase is small. With the reduction of the exposure time ratio, the $\mathrm{NH}_{4}{ }^{+}-\mathrm{N}$ concentration in the effluent increased first and then decreased, the TP concentration increased, and the TN concentration decreased first and then increased. When the exposure time ratio is $30 \mathrm{~min} / 30 \mathrm{~min}$, the TN concentration of the effluent is the lowest, about $27 \mathrm{mg} / \mathrm{L}$, the $\mathrm{NH}_{4}{ }^{+}-\mathrm{N}$ concentration of the effluent is about $16 \mathrm{mg} / \mathrm{L}$, and the TP concentration of the effluent is about $3.6 \mathrm{mg} / \mathrm{L}$. From the comprehensive comparison of effluent water quality, the exposure time ratio of $30 \mathrm{~min} / 30 \mathrm{~min}$ is the optimal stage.

This research was supported by the National Natural Science Foundation of China (No. 51308362).

\section{References}

1. X.-H. Wang, X. Wang, G. Huppes, R. Heijunge, N.-Q. Ren, Environmental implications of increasingly stringent sewage discharge standards in municipal wastewater treatment plants: case study of a cool area of China, Journal of Cleaner Production, 94 (2015) 278-283.

2. Q.H. Zhang, W.N. Yang, H.H. Ngo, W.S. Guo, P.K. Jin, M. Dzakpasu, S.J. Yang, Q. Wang, X.C. Wang, D. Ao, Current status of urban wastewater treatment plants in China, Environment International, 92-93 (2016) 1122.

3. W.F. Dong, F.U. De-Qian, Present Situation and Existing Problems and Countermeasures of Urban Wastewater Treatment Plants in China, Environmental Science Survey, (2008).

4. I. Zekker, E. Rikmann, T. Tenno, K. Kroon, P. Vabam?e, E. Salo, L. Loorits, S.S.C. dC Rubin, S.E. Vlaeminck, T. Tenno, Deammonification process start-up after enrichment of anammox microorganisms from reject water in a moving-bed biofilm reactor, Environmental Technology, 34 (2013) 3095-3101.

5. B. Stinson, M. Peric, D. Neupane, M. Laquidara, E. Locke, S. Murthy, W. Bailey, S. Kharkar, N. Passarelli, R. Derminassian, Design and Operating Considerations for a Post Denitrification MBBR to Achieve Limit of Technology Effluent NOx $<1 \mathrm{mg} / 1$ and effluent TP $<0.18 \mathrm{mg} / \mathrm{l}$, Proceedings of the Water Environment Federation, 2009 (2009) 1225-1254.

6. N.K. Singh, S. Pandey, R.P. Singh, S. Dahiya, S. Gautam, A.A. Kazmi, Effect of intermittent aeration cycles on EPS production and sludge characteristics in a field scale IFAS reactor, Journal of Water Process Engineering, 23 230-238.

7. S. Luostarinen, S. Luste, L. Valentin, J. Rintala, Nitrogen removal from on-site treated anaerobic effluents using intermittently aerated moving bed biofilm reactors at low temperature, Water Res, 40 (2006) 1607-1615.

8. M. Capodici, S. Fabio Corsino, F. Di Pippo, D. Di Trapani, M. Torregrossa, An innovative respirometric method to assess the autotrophic active fraction: Application to an alternate oxic-anoxic MBR pilot plant, Chem. Eng. J., 300 367-375. 